У, $\mathrm{K}$ K 32.01

ББК 66.04

DOI 10.22394/1682-2358-2019-2-118-125

Yu.D. Karyapkina, post graduate student of the Political Sciences Department, Povolzbsky Institute of Management named after P.A. Stolypin, Branch of the Russian Presidential Academy of National Economy and Public Administration

\section{THE ROLE OF PUBLIC ASSOCIATIONS IN THE PROCESS OF FORMING POLITICAL ELITES}

The key role of the political elite in the state government, as well as the nature of the formation of elites in Russia are considered. The analysis of the participation of public associations in the nomination of their representatives to the deputy corps of the regional centers of five constituent entities of the Russian Federation is carried out. The insignificance of the share of representative authorities deputies elected from public organizations is revealed.

Key words and word-combinations: political elite, elections, public associations, state policy, deputies, City Council.
Ю.А. Каряпкина, аспирант кафедрь политических наук Поволжского института управления имени П.А. Стольпина - филиала Российской академии народного хозяйства и государственной служби при Президенте РФ (email: 89271370252@mail.ru)

\section{РОАЬ ОБЩЕСТВЕННЫХ ОБЪЕАИНЕНИЙ В ПРОЦЕССЕ ФОРМИРОВАНИЯ ПОАИТИЧЕСКИХ ЭАИТ}

\begin{abstract}
Аннотация. Рассматривается ключевая роль политической элиты в управлении государством, а также характер формирования элит в России. Проводится анализ участия общественных объединений в выдвижении своих представителей в состав депутатского корпуса региональных центров четырех субъектов РФ. Выявлена незначительная доля депутатов, избранных в представительные органы власти от общественных организаций.

Ключевые слова и словосочетания: политическая элита, выборы, общественные объединения, государственная политика, депутаты, городская Дума.
\end{abstract}

$\Pi$ ринципиальным фактором эффективного государственного управления является качество правящей элиты. При этом имеется в виАу самый широкий смысл понимания таких качеств, как профессионализм, широта кругозора, нравственная принципиальность, идейная убежАенность, политическая сплоченность, близость к народу, служение и верность Отечеству. 
Совокупность этих качественных характеристик преАставцяется идеальной моделью, маловероятной дия конкретного преАставителя элиты, и выдвигается как требование Аля элиты в цемом. Подобный подход, как пишет Я.А. Пцяйс, преАставцяет собой не только академический, но и неоценимый практический интерес, ибо «... от качества элиты, прежде всего политико-административной, ее способности адекватно воспринимать ситуацию в стране и за ее пределами во всей ее сложности и противоречивости, зависит, может $и$ она не только верно определять алгоритм решения назревших проблем, но и методы и способы их реализации» $[1$, с. 65$]$.

Политическая элита современного государства представляет собой мощный институт вцияния на общество и государство, на весь процесс государственного управления. Именно эмита определяет стратегию развития, вырабатывает политический курс государства и организует общество на его реацизаџию. В этом отношении роль элиты значительнее роли политических партий, преАставительных органов вмасти, массовых общественных объединений. По мнению В.М. Аолгова и Т.В. Бирюлиной, «на уровне государственной политики элита регулирует демократические механизмы под реализацию своих интересов. Это относится и к правилам избирательного процесса, и к полномочиям институтов власти, и к функционированию структур гражданского общества» [2, с. 120]. Именно поэтому от уровня профессионализма и патриотизма эмиты в решающей степени зависит характер развития страны.

Эムита вырастает из общества и призвана представцять его интересы. Вхождение в элиту происходит разными путями, но чаще всего через рекрутирование, осуществляемое сверху, из рядов уже состоявшихся чиенов элиты. В этом случае, как показывает практика, новый член элиты всегда активен и прилежкен в реамизаџии интересов своих «патронов», которые не всегда совпадают с интересами населения. Второй путь вхождения в элиту - выдвижение общественно активных мюдей снизу, усилиями гражданского общества. При этом выдвиженец в состав эциты гораздо чаще служкит интересам общества, воспринимает его социальные, политические, культурные позиции. Естественно, исследование процесса формирования элиты, направленности ее интересов представцяет значительную актуальность Аля науки и Аля политической практики. Анализ данной проблемы с позищии участия общественных объединений в процессе формирования политической элиты на региональном уровне составцяет предмет данной статьи.

В отечественной науке основательно разработаны главные характеристики российской политической элиты. Широко известны труды А.К. Агапова, О.В. Гаман-Голутвиной, О.В. Крыштановской, А.В. Понеделкова, А.И. Соловьева, А.М. Старостина и Аругих исследователей, занимающихся различными аспектами элитологии. В научной митературе значительное внимание уделяется региональным эмитным группам, особенностям их развития, характеру взаимодействия с федеральными структурами государственного управления. А.В. Понеделков определяет региональную элиту «как социальную группу, чиены которой контролируют основные каналы влияния в регионе: административно-правовые, финансово-экономические, информационно-идеологические» [3, с. 218]. Он подчеркивает особое политическое значение региональ- 
ных элит, являющихся, по его мнению, проводниками общегосударственной политики на местах, кадровой основой функционирования механизмов госуАарственного управления [3, с. 216].

Ответственное место регионацьных элит в системе государственных институтов и реализаџии государственной политики объясняет научный интерес к проблеме их формирования, конкретным способам и механизмам этого процесса. В фундаментальной монографии О.В. Гаман-Голутвиной выявлено структурное разнообразие российской элиты, которое отражкается на региональном уровне. Сюда входят влиятельные персоны и группы, представцяющие органы законодательной и исполнительной власти, бизнес, высшую школу, СМИ, политические партии, силовые структуры, общественные организащии. В связи с этим О.В. Гаман-Голутвина вылемяет разцичные каналы рекрутирования региональных элит: федеральные и региональные властные структуры, органы местного самоуправления, коммерческие предприятия, политические партии, общественные объединения, СМИ, учреждения образования, кумьтуры, науки [4, с. 395]. Аанный ПодхоА вполне оправдан, что подтвержАается Политической практикой послеАних десятилетий, и все же не исчерпывает всего комплекса мероприятий по форми-

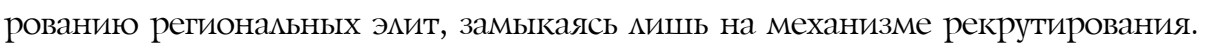

Бесспорно, механизм рекрутирования элиты в современных российских условиях является опредемяющим в формировании региональных элит. ОАнако нельзя игнорировать в этом проџессе значение механизма выдвижения представителей общества в состав элиты. Хотя он менее распространен в современной политической практике, но вцияет на проџесс формирования региональных элит. Механизм выдвижения используется в ходе избирательного процесса, когда активные участники общественной жизни выдвигаются кандидатами в депутаты разного уровня. В случае победы на выборах они приобретают статус представителя определенных групп населения и получают реальную возможность войти в состав региональной элиты. Но Ааже в случае поражения на выборах многие из состоявшихся «выдвиженцев» приобретают известность, накапиивают попуяярность, политический авторитет и тем самым входят в сферу общения и деятельности элитных групп.

Существенную роль в процессе выдвижения активистов в состав региональной элиты играют общественные объединения граждан. В 1990-е годы в регионах России происходия бурный процесс возникновения и активной Аеятельности общественных организаџий разнообразной направленности: природоохранных, профессиональных, военно-патриотических, научно-просветительских, этнических, религиозных, культурно-исторических, спортивнооздоровительных и многих Аругих. К настоящему времени сформировалась Аостаточно устойчивая структура таких организаций, опреАелилось их место в системе общественно-политических отношений. А.В. Баранов определяет общественные организации как инициативные, самостоятельные, самоуправмяемые объединения граждан, созданные Аля совместного решения общих Аля них проблем и защиты групповых интересов. По его мнению, такие объеАинения вовлекаются в политический проџесс и вступают в активные отношения и с государством, и с политическими элитами [5, с. 51; 59]. Следует 
подчеркнуть, что именно в контексте этих отношений происходит выдвижение активных, общественно-ответственных мюдей в разцичные органы госуАарственной вмасти или во вциятельные общественные структуры на уровне местного самоуправцения.

Общественные объединения граждан, бесспорно, преАставцяют собой основу гражкаанского общества. Гражданское общество включает в себя и добровольные ассоџиации, и свободные СМИ, и независимое экспертное сообщество, и профсоюзные организации трудящихся, и различные некоммерческие организации. На наш взглял, общественные объединения являются наиболее важным элементом гражданского общества, представцяют собой самые действенные его структуры [6]. Именно в деятельности общественных объединений осуществцяется становление, функционирование и развитие гражданского общества. Через их деятельность формируется конкретное взаимодействие институтов государственной власти и структур гражданского общества, в проџессе которого как раз и проявляются способные, эффективные кичности, Аелегируемые обществом в ряды политической эмиты и на федеральном, и на региональном уровне.

Существенное приращение возможностей проявления общественнополитической активности мюдей обеспечивают возникшие в 1990-е годы общественные палаты (ОП) субъектов РФ и лействующий с мая 2011 г. Общероссийский народный фронт (ОНФ). Общественные палаты в регионах способствуют объединению общественных организаций, укреплению их сотрудничества в совместном преАставительстве и защите интересов населения. Аеятельность общественных палат поставила на постоянную основу взаимоАействие общественных организаций и органов вмасти, в процессе которого возникали общественно-полезные деловые связи, конкретные контакты межАу чиновниками и общественниками. В этих условиях не толыко укреплялось взаимопонимание межАу полномочными представитецями государственной власти и общества, но более четкую форму обретали интересы насемения, средства и механизмы их реализации.

Общественные палаты в субъектах РФ, несомненно, обеспечивают проАвижкение перспективных общественников во властные структуры, в элитные слои. ОАнако проџесс формирования самих ОП, в котором полностью господствует администрирование и приоритеты правящей партии, существенно зауживает представленность в них общественных объединений и соџиальных групп. Кроме того, Аеятельность ОП нередко формализуется настолько, что их контакты с органами государственной и муниципацьной вцасти носят спонтанный характер, а экспертная функция ОП сводится к неизменному одобрению проектов документов и решений структур исполнительной и законодательной власти. В такой атмосфере процесс выдвижения активистов также формализуется и осуществляется без непосредственного участия общественности.

Еще более значимыми с точки зрения выдвижения новых активистов явмяются структуры ОНФ. Конечно, ОНФ создавался с непосредственной заАачей активизировать российское гражданское общество. Об этом заявлял В.В. Путин в момент организаџии ОНФ: «Мы создаем Общероссийский народный фронт Аля того, чтобы были востребованы все конструктивные идеи, 
чтобы у гражданского общества - молодежных, женских, ветеранских организаций, деловых кругов, профессиональных союзов, объединений - быма Аополнительная возможность непосредственно напрямую участвовать в выработке важнейших государственных решений» [7]. Отметим, что провозглашенная цель ОНФ на протяжении всех мет его политической деятельности реализуется достаточно успешно. Структуры ОНФ в центре и в регионах ведут активную работу по разоблачению фактов коррупции в органах власти, теневых сделок с бюджетными средствами, неэффективным использованием финансовых ресурсов, по борьбе с алкоголизмом, распространением наркотиков, продажей некачественных мекарств и продуктов питания, несправедиивыми судебными обвинениями и уголовными преследованиями и по многим Аругим вопросам. В работе по реализаџии общественного контроля активисты ОНФ нередко оппонируют органам вмасти и управления, отдельным чиновникам, вступают с ними в серьезные конфликты при отстаивании интересов общества и государства и ведут политическую борьбу против коррупционных проявлений.

Эффективность борьбы чиенов ОНФ за соџиальную справедиивость, соблюАение законности, за правду, способствует формированию общественной полАержки ОНФ со стороны гражАан. Неслучайно в течение послеАних Авух-трех цет многие активисты ОНФ приобрели всероссийскую известность, заняли высокие государственные Аолжности в федеральном и региональных органах исполнительной власти, в Государственной Ауме РФ, в органах законодательной вцасти субъектов РФ. Они оказались полномочными представителями общества, выдвинутыми в состав политической элиты.

Тем не менее существующее состояние взаимодействий структур гражданского общества и институтов государственной вмасти малоэффективно. Эксперты отмечают ослабление функциональности общественных палат в качестве связующего звена межАу обществом и властью. Е.М. Шульман по материалам анациза, проведенного Комитетом гражданских иниџиатив, пишет о том, что в последние годы состав общественных палат изменияся в пользу назначенцев исполнительной власти и за счет сокращения преАставителей общественных организаций, реальных выразителей общественного мнения [8]. Федеральная и региональная бюрократия заинтересована в сохранении контроля наА деятельностью общественных палат, упрощая дия себя управленческий процесс, но делая при этом его менее эффективным. В.А. Труханов раскрывает сощиальные и общественно-политические факторы, тормозящие развитие гражАанского общества, общественной активности населения [9]. Существенным фактором явмяется чрезмерный государственный бюрократизм. Ученые $\Lambda$ аборатории проблем повышения эффективности и государственного и муниципального управления ЮРИУ РАНХиГС подчеркивают необходимость демократизаџии политической системы Российской Федераџии через целенаправленное взаимодействие политической элиты и гражданского общества, что реацьно, но мишь при активной гражданской позиции населения [10].

К этому следует Аобавить, что и общественные палаты регионов, и структуры ОНФ тесно сотрудничают только с оАной политической партией - правящей «ЕАиной Россией». Их контакты с оппозиционными политическими 
партиями минимизировались. Хотя такое положение вписывается в могику современных политических отношений, оно все же ограничивает возможности гражданского общества по взаимодействию с властями, тем более по вциянию на проводимую регионацьную политику.

Материалы проведенного исследования подтверждают эти экспертные заключения. Содержание научного исследования составляет анализ данных избирательных кампаний муниципального уровня на предмет результативности участия в них представителей общественных организаций. Объектом исследования избраны городские представительные органы региональных центров четырех субъектов РФ: Воронежа (ЦФО); Самары, Саратова (ПФО); Краснодара (ЮФО).

Аанные регионы представцяют разцичные субъекты РФ, но наряду с этим обладают множеством бцизких характеристик (экономических, политических, социокультурных, национальных). Численность населения субъектов, рассматриваемых в Аанном исследовании, находится в Аиапазоне от 800000 до 1200000 человек. Период исследования охватывает по три последних выборных кампании. Основной источниковой базой служат официальные сайты избирательных комиссий Воронежской, Самарской, Саратовской областей и Краснодарского края [11-14].

По данным выборов в Воронежскую городскую Ауму, в 2005 г. (231 канАидат) в нее был избран один депутат от общественной организации (КоорАинационный совет содействия предприниматемям), и это составляло 3,5\% от всего состава депутатов; в 2010 г. (150 кандидатов) - один депутат (Областная общественная организащия «Галерея Чижова») - 2,8\% от общего состава; в 2015 г. (551 кандидат) не избрался ни один представитель общественных организаций. Неизбранными оказались кандидаты в депутаты в 2005 г. - от 18 организаций, в 2010 г. - от 4, а в 2015 г. - от 15 общественных организащий.

На выборах в Самарскую городскую Ауму 2004 г. (262 кандидата) было избрано пять преАставителей общественных организаций (от профсоюзного комитета ОАО «Самарский завоА Электрощит»; первичной профсоюзной организации ОАО «Самарский метамургический завоА»; Самарской региональной организации Общероссийской общественной организаџии инвалидов войны в Афганистане; областной организации Российского союза ветеранов Афганистана; Самарского Союза народного самоуправления; на выборах в 2010 г. (299 кандидатов) - пять представителей (от единой первичной профсоюзной организации «Экектрощит»; первичной профсоюзной организации ОАО «Самарский метамлургический завод»; попечительского совета Самарской региональной общественной благотворительной организаџии соџиальной поддержкки и защиты гражжаан; Самарской региональной организации Общероссийской общественной организации инвалидов войны в Афганистане; Нотариальной палаты Самарской области. Избранные депутаты от общественных объединений составляли в Самарской городской Ауме: 15,1\% от всего состава депутатов. Большое количество кандидатов от общественных организаџий в Самарскую городскую Ауму оказамось неизбранным: в 2004 г. - от 18; в 2010 г. - от 10 организаций.

На выборах в Саратовскую городскую Ауму 2006 г. (252 кандидата) было избрано три депутата от общественных организаций: Саратовской областной 
комегии адвокатов, Саратовского областного объединения профсоюзов, Ассоциаџии торгово-промышиенной группы «Славянский мир»; на выборах 2011 г. (366 кандидатов) избрано депутатами два представителя общественных организаций: от Ассоџиаџии ТПГ «САавянский мир» и профсоюзной организации студентов Саратовского государственного университета им. Н.Г. Чернышевского; на выборах 2016 г. (471 кандидат) избрано два представителя общественных организаций: благотворительного фонда Концерна «Аубки» и Ассоциации ТПГ «САавянский мир». Характерно, что на каждых выборах большое число кандидатов от общественных организаций не избиралось в состав Аепутатов: в 2006 г. - от 13 организаџий, в 2011 г. - от 11, в 2016 г. от 17 общественных организащий. Избранные депутатами от общественных организаций составцяли в Саратовской городской Ауме $12 ; 8,5 ; 5 \%$ от общего числа членов. Вполне очевидна тенденция к снижению уровня представительства общественных организаций в депутатском корпусе г. Саратова.

Анализ выборов в Краснодарскую городскую Ауму показал следующие результаты: в 2005 г. (312 кандидатов) бым избран один депутат от Ассоциации «Аегковое такси»; в 2010 г. (278 кандидатов) не были избраны представители общественных и иных организаций; в 2015 г. (566 кандидатов) избран один Аепутат, представитель Ассоциации Краснодарской краевой комлегии аАвокатов ААвокатской палаты Краснодарского края. Избранные депутаты от общественных объединений составляли в городской Ауме Краснодара соответственно 2,5; 0 и 3,7\% от всего состава. Неизбранными оказались кандидаты в депутаты в 2005 г. - от 17 организаций; в 2010 г. - от 10 организаций; в 2015 г. - от 14 организаций.

По нашему мнению, уровень участия структур гражданского общества в формировании политической элиты является важной характеристикой демократичности политической системы мюбого государства. Аанный фактор свидетельствует о характере народного преАставительства в системе государственного управцения, о качестве взаимодействия общества и власти, об эффективности отражения интересов населения в государственной политике. Проведенный анализ масштабов выдвижения общественников в состав депутатского корпуса столичных центров субъектов РФ показывает явно недостаточный уровень участия общественности в территориальном и государственном управлении. Полное преимущество в формировании региональных политических элит имеют органы исполнительной власти и Всероссийской политической партии «ЕАиная Россия».

Конечно, выдвижение, а тем более регистращия кандидатов избирательными комиссиями происходит практически полностью на партийной основе. Политические партии заполняют своими представителями списки кандидатов, фактически не оставцяя в них места Аля выдвиженцев общественных организаций. Это относится ко всем видам выборов регионального и муниципального уровня. В конечном счете избиратели получают ограниченные возможности голосования за выдвиженцев из общества, и представительные органы вмасти в регионах на 85-95\% формируются партийными назначенџами, ибо все партийные списки кандидатов формируются в партийных штабах. 
Подобная ситуация отриџательно сказывается на электоральной активности. Не случайно процент явки избирателей на последних двух-трех выборах в большинстве российских регионов остается крайне низким, порой не доходя даже до 25-30\%. На выборах же в сельские администрации явка избиратемей нередко бывает настолько низкой, что трудно говорить об их мегитимности. В результате, как подчеркивает Ю.А. Александрова, «получившие широкое распространение элементы взаимодействия граждан с вмастными структурами сформировали представление об отсутствии действенных механизмов реамизаџии общественных запросов. При принятии важных Аля города решений мнение граждан не учитывается» $[15$, с. 12].

Все это в совокупности, по нашему мнению, ограничивает развитие гражАанского общества, сдерживает проџесс демократизаџии государственной и муниципальной власти. Расширение масштабов вовлечения представителей обшественности в управление государством, пополнение политической элиты активными представителями гражданского общества, безусловно, будет способствовать повышению качества государственной политики на всех уровнях ее реализации [16].

\section{Библиографический список}

1. Пляйс Я.А. Марксизм и социальные революции в России. М., 2019.

2. Долгов В.М., Бирюлина Т.В. Демократия, элиты и национальные интересы // Вестник Поволжского институт управления. 2018. Т. 18, № 1. С. 113-123.

3. Понеделков А.B. Политико-административные элиты России. Ростов н/Дону, 2005.

4. Гаман-Голутвина О.В. Политические элиты России: Вехи исторической эволюции. М., 2006.

5. Баранов A.B. Общественные объединения и социальные сети: роль в политическом процессе Краснодарского края // PolitBook2. 2012.

6. Фадеева А.Н. Партнерские отношения между государством и гражданским обществом: необходимость и проблемы становления // Вестник Саратовской государственной юридической академии. 2017. № 6 (119). С. 52-57.

7. Путин В.В. Выступление на встрече с представителями актива Общероссийского народного фронта 12 мая 2011 г., г. Сочи. URL: http://archive.premier.gov.ru/events/news/15150/

8. Сигнал не проходит. Что мешает Общественной палате доносить до власти мнение россиян (22 февр. 2017 г.) // Lenta.Ru. URL: https://enta.ru/articles/2017/02/22/palata/

9. Труханов В.А. Гражданское общество в политическом процессе современной России: проблемы становления // Актуальные проблемы гуманитарных и социально-экономических наук. 2018. Т. 12, № 4. С. 126-129.

10. Аствачатурова М.А., Понеделков А.В., Воронщов С.А., Игнатова Т.В. Императивы формирования гражданского единства: экспертные оценки // Государственное и муниципальное управление. Ученые записки. 2018. № 2. С. 11-16.

11. Сайт избирательной комиссии Воронежской области. URL: http://www.voronezh.izbirkom.ru/-523238574

12. Сайт избирательной комиссии Самарской области. URL: http://www.samara.vybory. izbirkom.ru/region/samara

13. Сайт избирательной комиссии Саратовской области. URL: http://www.saratov.izbirkom.ru/

14. Сайт избирательной комиссии Краснодарского края. URL: http://www.krasnodar.vybory. izbirkom.ru/region/krasnodar

15. Александрова Ю.А. Общественно-политические отношения в современной России: к вопросу об оценке степени консолидации и дезинтеграции // Вестник Поволжского института управления. 2017. Т. 17, № 2. С. 11-16. 